\title{
SSynthesis
}

International Scientific Conference of IT and Business-Related Research

\section{POREĐENJE PERFORMANSI RAZLIČITIH METODA DETEKCIJE IVICE U DIGITALNOJ SLICI}

\section{PERFORMANCE EVALUATION OF DIFFERENT DIGITAL IMAGE EDGE DETECTION METHODS}

\author{
Hana Stefanović1, Svetlana Štrbac-Savić1 ${ }^{1}$ Dejan Milić ${ }^{2}$ \\ ${ }^{1}$ Visoka škola elektrotehnike i računarstva strukovnih studija u Beogradu, Vojvode Stepe 283, Beograd, Srbija \\ ${ }^{2}$ Elektronski fakultet Univerziteta u Nišu, Katedra za Telekomunikacije, Aleksandra Medvedeva 14, Niš, Srbija
}

\begin{abstract}
Apstrakt:
U radu su obrađeni neki od standardno korišćenih algoritama za detekciju ivice u slici, što je jedan od najznačajnijih koraka u interpretaciji sadržaja digitalne slike. Analizirani su gradijentni operatori za izdvajanje ivice bazirani na digitalnim aproksimacijama prvog izvoda dvodimenzionalne funkcije gradijenta slike, a praktična implementacija urađena je u MATLAB programskom okruženju. Ilustrovana je primena Roberts-ovog, Prewitt-ovog, Sobel-ovog i Canny-jevog detektora, a nakon analize i poređenja dobijenih rezultata, predloženi su neki algoritmi povezivanja ivica u cilju formiranja neprekidnih granica regiona, uz upotrebu različitih metoda fitovanja krivih. Negativan uticaj šuma pri izdvajanju ivica delimično je eliminisan primenom prostornog usrednjavanja prilikom formiranja razlike osvetljenosti po određenoj koordinati, pri čemu se prostorno usrednjavanje vrši po ortogonalnoj koordinati. Uticaj parametra koji kontroliše proces usrednjavanja posebno je razmotren u slučaju Canny-jevog detektora. Konkretni primeri koji ilustruju upotrebu različitih vrsta detektora, uz poređenje sa originalnom slikom, rađeni su u MATLAB programskom okruženju, dok su, osim subjektivne vizuelne ocene kvaliteta, određeni i numerički pokazatelji kvaliteta kao što su srednja kvadratna greška (MSE - Mean-Square Error) i vršni odnos signal-šum (PSNR - Peak Signal-to-Noise Ratio).
\end{abstract}

\section{Key words:}

detekcija ivice, gradijentni operatori, segmentacija, aproksimacija krivih.

\section{UVOD}

Izdvajanje obeležja (features) iz slike, u cilju vršenja računarske interpretacije i dalje analize slike pomoću izdvojenih obeležja, ima značajnu primenu u različitim oblastima, kao što su analiza medicinskih snimaka, identifikacija u sistemima za razvrstavanje pošte, navođenje projektila u vojnim primenama, itd. (Popović, 2006).

Algoritmi za analizu slike su slični klasičnim algoritmima za prepoznavanje oblika, a izlaz ovakvog sistema nije slika, nego numerički ili simbolički opis njenog sadržaja (Trussel \& Vrhel, 2008). Osim procesa izvdvajanja obeležja, u procesu analize slike važan je i postupak segmentacije, kao i opis i interpretacija same scene (Senthilkumaran \& Rajesh, 2009). Uobičajeno je da se ulazna slika prvo obradi nekim od postupaka za popravku kvaliteta, odnosno postupcima restauracije, a da se nakon toga vrši izdvajanje karakterističnih obeležja. Nakon izdvajanja obeležja sledi proces razdvajanja regiona na sceni, odnosno segmentacija. U ovom radu je analizirana jedna od tipskih slika iz MATLAB programskog okruženja, koja predstavlja realnu scenu, a sprovedeni su različiti postupci izdvajanja obeležja, kao i postupak segmentacije.

\section{Abstract:}

The paper analyses some of the standard edge detection algorithms, as one of the key steps towards interpreting digital image properties. We performed the analysis of edge detection gradient-based operators based on the digital approximations of the first derivative of the twodimensional image gradient function, while practical implementation was done in MATLAB programming environment. The comparative analysis of different edge detection algorithms is presented, including Roberts, Prewitt, Sobel and Canny method. Upon the analysis and comparison of the results obtained, some edge detection algorithms were proposed in order to form sequential edge points, using different curve fitting methods. The negative impact of image noise, resulting in pixels that look very different from their neighbours, is reduced by averaging and smoothing image, in order to discount localized noise pixels. The impact of the parameter controlling the process of spatial averaging is particularly considered in the case of Canny edge detector. The concrete examples illustrate the use of various types of detectors, compared to the original image in MATLAB programming environment. Besides the subjective visual assessment of the quality, numerical quality indicators such as MSE - Mean-Square Error, and PSNR - Peak Signal-to-Noise Ratio) were identified.

\section{Ključne reči:}

edge detection, gradient-based operator, segmentation, curve fitting.

Izdvajanje obeležja je izvršeno upotrebom različitih algoritama za detekciju ivice (edge detection), što je jedan od najvažnijih i najčešće korišćenih postupaka u analizi slike (Pratt, 2007). Ivica predstavlja lokalni diskontinuitet osvetljenosti na slici, dajući dobru indikaciju granica objekata na sceni, što se dalje može koristiti u postupku segmentacije, registracije i same identifikacije objekata na sceni (Russ, 2002).

U radu su korišćene neke od ugrađenih funkcija za izdvajanje ivica u MATLAB programskom okruženju (Gonzales $e t$ al., 2009), a predložene su i neke modifikacije, dok je proces segmentacije ilustrovan na primeru iste slike čije su ivice izdvajane različitim detektorima.

Detekcija ivice u slici se najčešće vrši selektovanjem piksela u čijem susedstvu nastaje nagla promena nivoa sivog. Najjednostavnije metode koriste se u sličaju binarne slike, dok se u slučaju slike sa većim brojem nivoa sivog selekcija ivičnih piksela uglavnom vrši metodama diferencijalne detekcije ili poređenjem sa modelom ivice (Oskoei \& Hu, 2010). U radu su analizirane diferencijalne metode detekcije, zasnovane na aproksimaciji prvog ili drugog izvoda slike (Pinho \& Almeida, 1997). Izabrana je slika koja predstavlja realnu scenu (cameraman.tif) da bi se kvalitetnije uporedila efikasnost korišćenih 
algoritama i u slučaju ivica slabijeg intenziteta, kao i u slučaju ivica manje strmine promene intenziteta, što je tipično za realne scene.

Korišćeni su gradijentni operatori zasnovani na digitalnim aproksimacijama prvog izvoda dvodimenzionalne funkcije gradijenta, koji je predstavljen vektorom koji određuje intenzitet i smer maksimalne brzine promene funkcije.

\section{DETEKTORI BAZIRANI NA GRADIJENTNIM OPERATORIMA}

Gradijentni operatori za izdvajanje ivice bazirani su na digitalnim aproksimacijama prvog izvoda dvodimenzionalne funkcije gradijenta, koji pokazuje intenzitet i smer maksimalne brzine promene funkcije $f(x, y)$ :

$$
G[f(x, y)]=\nabla f(x, y)=\left[\begin{array}{ll}
\frac{\partial f}{\partial x} & \frac{\partial f}{\partial y}
\end{array}\right]^{T}
$$

U slučaju digitalne slike $f(m, n)$ parcijalni izvodi se aproksimiraju količinama konačnih priraštaja, odnosno konvolucijama određenim sa (Popovic, 2006):

$$
\begin{aligned}
& G_{x}[m, n]=f(m, n) * h_{x}(m, n)=\sum_{k=-p}^{p} \sum_{l=-p}^{p} h_{x}(k, l) f(m-k, n-l) \\
& G_{y}[m, n]=f(m, n) * h_{y}(m, n)=\sum_{k=-p}^{p} \sum_{l=-p}^{p} h_{y}(k, l) f(m-k, n-l)
\end{aligned}
$$

pri čemu $\mathbf{H}_{x}$ i $\mathbf{H}_{y}$ predstavljaju odgovarajuće matrice ili maske dimenzija $(2 p+1)^{\star}(2 p+1)$, a $p$ predstavlja prirodan broj. Maske služe za aproksimaciju projekcija gradijenta slike na $x \mathrm{i}$ $y$ osu. Amplituda gradijenta se određuje kao:

$$
G[m, n]=\sqrt{G_{x}^{2}[m, n]+G_{y}^{2}[m, n]}
$$

dok je argument gradijenta određen sa:

$$
\theta_{G}[m, n]=\arctan \left(G_{y}[m, n] / G_{x}[m, n]\right)
$$

Piksel na lokaciji $(m, n)$ se proglašava ivičnim, ako je amplituda gradijenta veća od nekog unapred definisanog praga $G_{T}$, dok se nakon definisanja i određivanja ivičnih piksela formira mapa ivica $E(m, n)$.

Najjednostavnija aproksimacija komponenata gradijenta dobija se formiranjem razlika osvetljenosti piksela duž vrsta i kolona slike, što daje dobre rezultate za slučaj strmih ivica, dok u slučaju ivica slabijeg intenziteta daje lošu lokalizaciju, odnosno loše određuje položaj ivice (Gonzalez \& Woods, 2008). Na ovom principu zasnovan je Robertsov operator (Pratt, 2007), koji se koristi i za izoštravanje slike. Razlike osvetljenosti su formirane tako da se forsira dobro izdvajanje dijagonalnih ivica, a u skladu sa tim su definisane i odgovarajuće maske Robertsovog operatora (Popovic, 2006).

Ilustracija izdvajanja ivica slike cameraman.tif Robertsovim operatorom prikazana je na Slici 1.

Nedostatak Robertsovog algoritma je velika osetljivost na šum, odnosno na male fluktuacije osvetljenosti piksela slike,
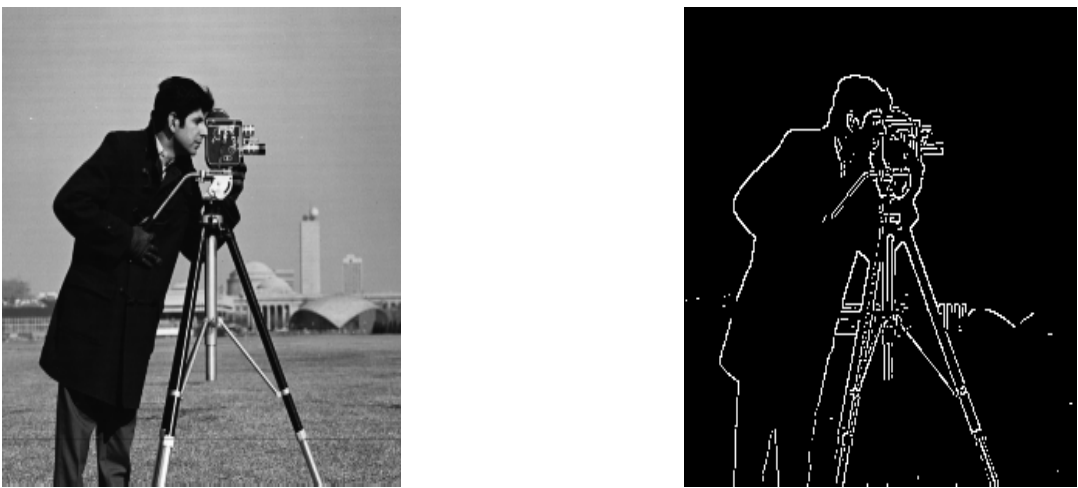

Slika 1. Rezultat izdvajanja ivica Robertsovim detektorom
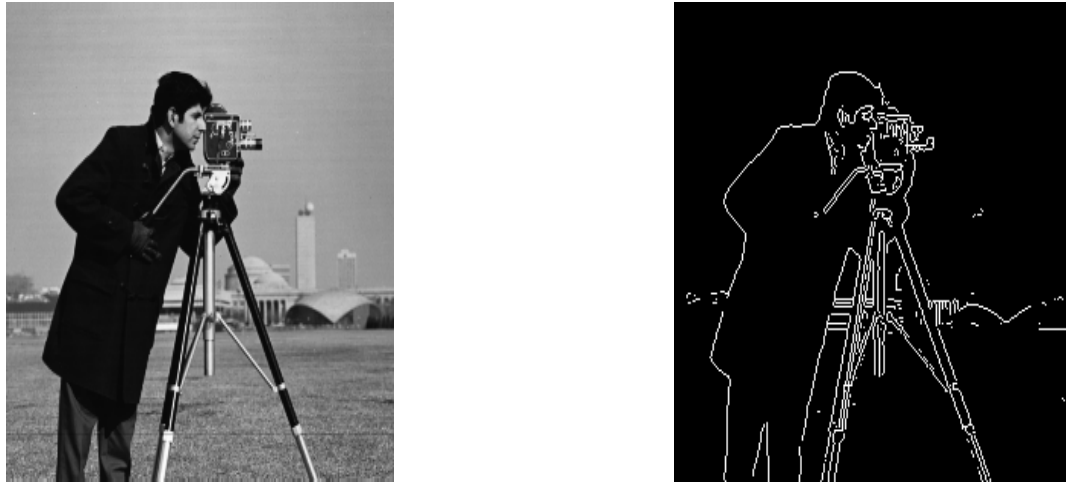
usled čega se mogu pojaviti lažne ivice ili izolovane tačke. U cilju potiskivanja šuma pri formiranju mape ivica mogu se koristiti veće vrednosti praga $G_{T}$, ali uz rizik gubljenja pravih ivica manjeg intenziteta.

U cilju delimične eliminacije negativnog uticaja šuma, prilikom formiranja razlike osvetljenosti po jednoj koordinati, može se istovremeno primeniti i prostorno usrednjavanje po ortogonalnoj koordinati, što se koristi u Previtovom algoritmu izdvajanja ivice (Popović, 2006; Gonzalez \& Woods, 2008).

Ilustracija izdvajanja ivica slike cameraman.tif Previtovim operatorom prikazana je na Slici 2.

Za razliku od Previtovog operatora koji koristi usrednjavanje bez težine, težinsko usrednjavanje primenjeno je u slučaju Sobelovog operatora, sa ciljem da se svim pikselima obezbedi odgovarajući uticaj u formiranju gradijenta (Popović, 2006; Gonzalez \& Woods, 2008).

Ilustracija izdvajanja ivica slike cameraman.tif Sobelovim operatorom prikazana je na Slika 3.

Jednaku vrednost gradijanta za horizontalne, vertikalne i dijagonalne ivice obezbeđuje izotropni gradijentni operator ili Frei-Čenov operator sa optimizovanom vrednošću parametra usrednjavanja (Frei \& Chen, 1977). Svi operatori koji koriste i prostorno urednjavanje po ortogonalnoj koordinati, svakako daju bolje rezultate u pogledu generisanja lažnih ivica ili izolovanih tačaka, u odnosu na operatore zasnovane na razlikama.

Proširivanjem granica lokalnog susedstva na kome se izračunava aproksimacija gradijenta rezultuje još boljim potiskivanjem šuma, na osnovu čega su projektovani bokskar (boxcar) operatori sa maskama većih dimenzija. Uvođenjem težinskih koeficijenata u proces usrednjavanja pri izračunavanju gradijenta dobijen je i piramidalni operator koji je predložio Abdou (Abdou \& Pratt, 1979). Dalja optimizacija sprovodi se uvođenjem težinske funkcije Gausovskog oblika u proces usrednjavanja, što je predložio Argile, a koristi se i u Makleodovom algoritmu detekcije ivice (Macleod, 1970).

Svi navedeni operatori koriste kombinovano operacije usrednjavanja i operacije formiranja razlike, a u slučaju upotrebe težinske funkcije Gausovskog oblika parametar kojim je određena standardna devijacija kontroliše proces usrednjavanja (Basu, 2002). Optimalan izbor ovog parametra predstavlja kompromis između dobre detekcije i dobre lokalizacije ivice.

Prethodno prikazani gradijentni operatori dobijeni su na heuristički način, a u cilju komparativne analize u radu su ilustrovani i rezultati primene Kanijevog operatora do kojeg se dolazi analitičkim pristupom (Canny, 1986). U izvođenju Kanijevog operatora polazi se od jednodimenzionalne kontinualne idealno strme ivice kojoj je superponiran beli Gausov šum standardne devijacije $\sigma_{n}$, dok se izdvajanje ivica vrši konvolucijom u kontinualnom domenu signala ivice sa šumom, sa antisimetričnim impulsnim odzivom operatora, koji ima nenultu vrednost $\mathrm{u}$ određenom intervalu (Popović, 2006). Položaj ivice je određen lokalnim maksimumom te konvolucije, dok su osnovni kriterijumi za određivanje impulsnog odziva operatora dobra detekcija, dobra lokalizacija i širina ivice ograničena na jedan piksel. Postupak optimizacije se zbog velike složenosti vrši numerički. Za Kanijev algoritam karakterističan je postupak potiskivanja
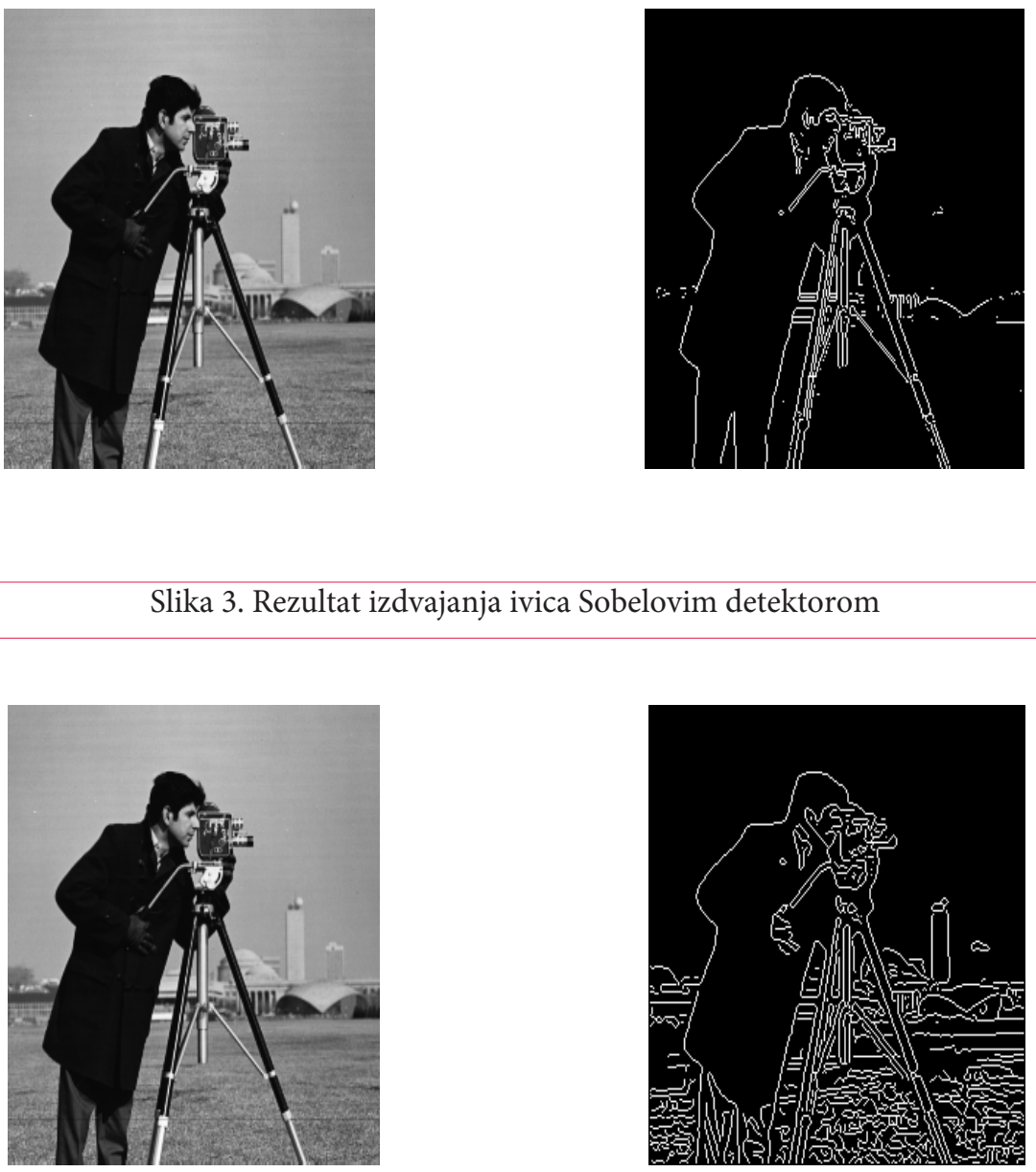
ne-maksimuma (non-maximum suppression) nakon formiranja gradijentne slike. U procesu potiskivanja ne-maksimuma vrši se poređenje modula gradijenta za svaki piksel sa vrednostima gradijenta u dve tačke koje su postavljene ekvidistantno sa obe strane ivice, a vrednost gradijenta se zadržava samo ako je veća od obe vrednosti sa kojima se poredi (Canny, 1986). Nakon potiskivanja ne-maksimuma vrši se poređenje sa unapred definisanom vrednošću praga u cilju formiranja binarne mape ivica.

Ilustracija izdvajanja ivica slike cameraman.tif Kanijevim operatorom prikazana je na Slici 4 , uz očiglednu prednost u odnosu na prethodno prikazane postupke.

$\mathrm{Na}$ osnovu vizuelnog poređenja sa prethodno ilustrovanim rezultatima izdvajanja ivica koristeći Robertsov, Prewitt-ov i Sobelov operator, može se zaključiti da Kanijev detektor obezbeđuje najbolju detekciju ivica, kao i da u generisanoj mapi ivica sve ivice imaju odgovarajuću širinu, odnosno da nije potreban postupak stanjivanja ivica koji je u slučaju primene nekih operatora neophodan.

Kanijev algoritam takođe ima i mogućnost promene vrednosti parametra $\sigma$ u cilju postizanja komprimisa između dobre detekcije i dobre lokalizacije. Određivanje optimalne vrednosti praga detekcije u Kanijevom algoritmu deteljno je analizirano u literaturi, a osnovna ideja je da se odredi vrednost parametra $\sigma$ koja smanjuje devijaciju gradijenta usled šuma na vrednost koja odgovara verovatnoći lažne detekcije (Amodaj \& Popović, 1990).

\section{POREĐENJE PERFORMANSI OPISANIH DETEKTORA}

Definisanje i poređenje različitih metoda za izdvajanje ivica je vrlo kompleksno, pošto postoji veliki broj metoda čije je optimalne vrednosti slobodnih parametara teško odrediti, a takođe je problematičan i izbor mape ivica sa kojom će se porediti dobijeni rezultati (Shin, 2001). U ovom radu je kao mapa za poređenje izabrana mapa ivica dobijena Kanijevim algoritmom, zbog očigledne prednosti u odnosu na ostale postupke analizirane u ovom radu. Kvalitet opisanih detektora procenjen je određivanjem standardno korišćenih numeričkih pokazatelja kvaliteta, kao što su srednja kvadratna greška (MSE - MeanSquare Error) i vršni odnos signal-šum (PSNR - Peak Signal-toNoise Ratio), a poređenje je vršeno u odnosu na Kanijevu mapu.

Za slike $x\left(n_{1}, n_{2}\right)$ i $y\left(n_{1}, n_{2}\right)$ dimenzija $N_{1} \times N_{2}$, MSE se određuje kao (Pratt, 2007):

$$
M S E=\frac{1}{N_{1} N_{2}} \sum_{n_{1}=1}^{N_{1}} \sum_{n_{2}=1}^{N_{2}}\left[x\left(n_{1}, n_{2}\right)-y\left(n_{1}, n_{2}\right)\right]^{2}
$$

dok je PSNR određen sa:

$$
P S N R=10 \log _{10}\left(\frac{M A X_{I}}{M S E}\right)
$$

pri čemu $M A X_{I}$ predstavlja najveću moguću vrednost piksela, koja u slučaju osmobitne sivo-skalirane slike iznosi 255.

Nakon proračuna vrednosti PSNR [dB] dobijene su vrednosti: $10.45 \mathrm{~dB}, 11.25 \mathrm{~dB}$, i $11.19 \mathrm{~dB}$, za Robertsov, Previtov i Sobelov detektor, respektivno, na osnovu čega se može zaključiti da je najmanja razlika u odnosu na optimalni Kanijev detektor postignuta u slučaju upotrebe Previtovog algoritma, nešto veća u slučaju upotrebe Sobelovog detektora, a da su najlošiji rezultati postignuti u slučaju primene Robertsovog detektora, što je u skladu i sa subjektivnom vizuelnom ocenom kvaliteta mape izdvojenih ivica.

\section{SEGMENTACIJA SLIKE NA OSNOVU MAPE IVICA}

Postupak segmentacije predstavlja podelu slike na regione sa sličnim atributima, pri čemu se kao atribut najčešće koristi osvetljenost (kod monohromatskih slika) ili boja (kod kolornih slika). U procesu segmentacije mogu se koristiti i drugi atributi kao što su ivice ili mera teksture (Senthilkumaran \& Rajesh, 2009). U ovom radu je kao atribut korišćena prethodno generisana mapa ivica.

Većina postupaka segmenatacije je heurističkog karaktera, dok se u praksi uglavnom koristi opisna kvalitativna definicija dobre segmentacije (Senthilkumaran \& Rajesh, 2009; Popović, 2006).

Ilustracija postavljanja granica regiona, sa ciljem da granice budu jednostavne, glatke i prostorno što tačnije, prikazana je na Slici 6 a) i b), nakon primene Kanijevog algoritma za izdvajanje ivice, sa parametrom standardne devijacije $\sigma=1$ i pragom definisanim vektorom [0.1 0.2$]$. Rezultat primene Kanijevog detektora sa donjom i gornjom granicom praga definisanom prethodnim vektorom, prikazan je na Sl. 5 .

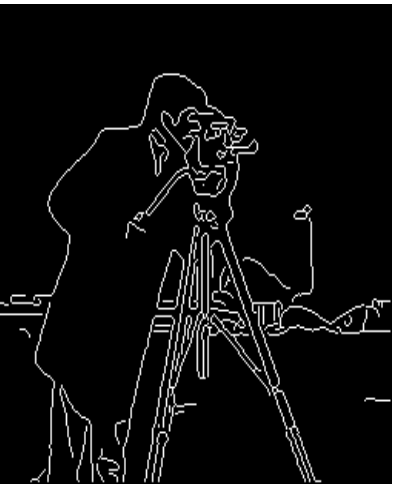

Slika 5. Mapa ivica dobijena Kanijevim detektorom sa parametrom standardne devijacije $\sigma=1$ i pragom definisanim vektorom [0.1 0.2$]$

Na Slici 6 a) i b) ilustrovana je segmentacija scene određivanjem granice objekata na osnovu prethodno generisane mape ivica.

Posledica postojanja šuma u slici je isprekidanost granica objekata, a iz tih razloga se u praksi koriste različiti postupci spajanja ivica u cilju formiranja neprekidnih granica regiona. Prilikom povezivanja ivica ilustrovanog na Sl. 6 segmenti dužine manje od 10 piksela nisu uzimani u obzir. Nakon toga je vršeno spajanje ivica aproksimacijom krivih, u cilju rekonstrukcije nedostajućih segmenata. U literaturi su opisani različiti algoritami aproksimacije, kao što je aproksimacija Bezier-ovim polinomima ili splajnovima, zatim iterativni metodi aproksimacije pravolinijskim segmentima, a predloženi su i različiti heuristički načini spajanja ivica.

U primeru ilustrovanom Slikom 6 b) segmenti krivih fitovani su sa maksimalnom devijacijom u odnosu na original $u$ vrednosti 2 piksela, a nakon aproksimacije svi segmenti su prikazani različitim bojama, pri čemu je izbor boje za prikazivanje slučajnog karaktera. 

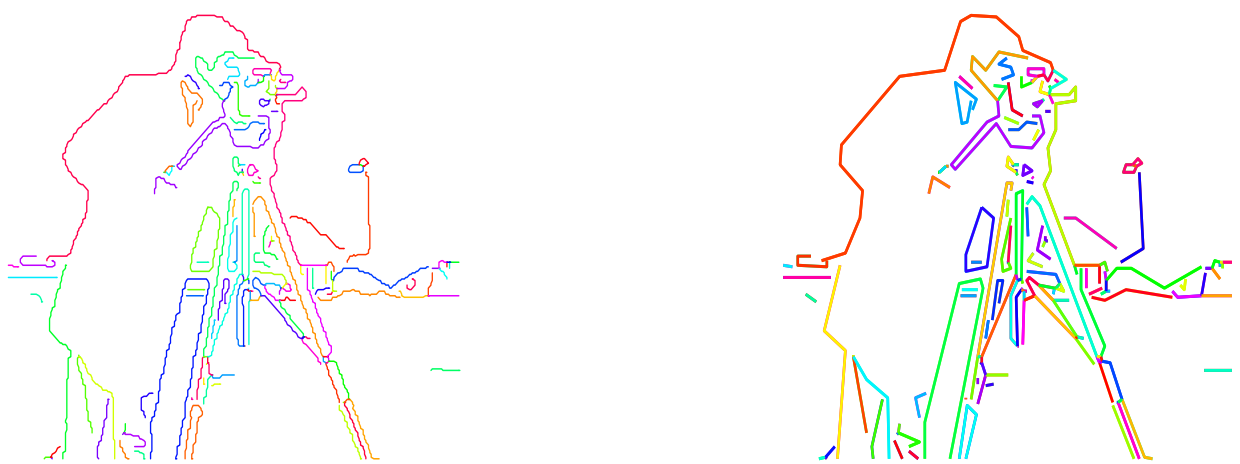

Slika 6. a) Segmentacija i b) fitovanje sa maksimalnom devijacijom u odnosu na original u vrednosti 2 piksela
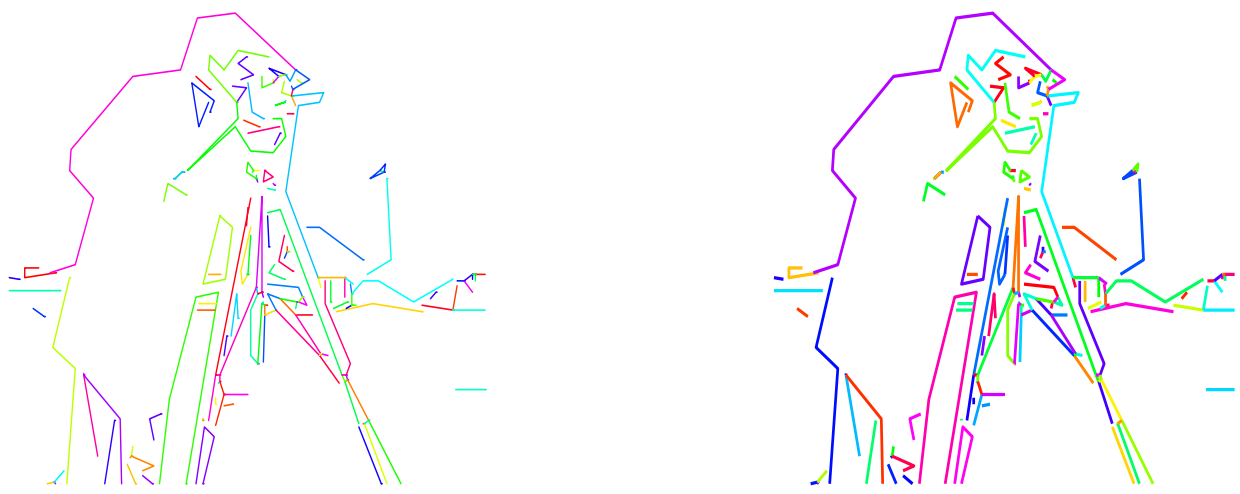

Slika 7. a) Segmentacija i b) fitovanje sa maksimalnom devijacijom u odnosu na original u vrednosti 3 piksela

U slučaju izbora većih vrednosti maksimalne devijacije u odnosu na original, nakon aproksimacije dobiće se lošiji rezultati, što je prikazano na Slici 7 a) i b).

Na Slici 7 b) ilustrovan je postupak aproksimacijie nakon izbora maksimalne vrednosti devijacije u vrednosti 3 piksela, uz očigledno lošije performanse u odnosu na rezultat prikazan na Slici 6 b).

\section{ZAKLJUČAK}

U radu je ilustrovana praktična implemantacija različitih algoritama za detekciju ivice u digitalnoj slici, baziranih na gradijentnim operatorima, uz očiglednu prednost Kanijevog algoritma u odnosu Robertsov, Previtov i Sobelov, za pretpostavljene uslove.

Nakon primene različitih detektora, mapa ivica je dopunjena nedostajućim pikselima koristeći jednostavnije metode fitovanja krivih, u cilju dobijanja glatkih prostorno što tačnijih regiona.

Ilustrovani algoritmi bi se mogli efikasno primeniti za odvajanje predmeta od pozadine, naročito u slučajevima kada pozadina ima uniformnu ili približno uniformnu osvetljenost, različitu od osvetljenosti predmeta na slici, što je tipično za prepoznavanje tipa automobila ili aviona na snimku ili slici, kao i u slučaju raznih biomedicinskih slika.

Jedna od značajnih primena predstavljanja slike pomoću ivica objekata prisutnih u snimljenoj sceni je svakako smanjenje količine podataka koje je potrebno obraditi, zadržavajući pri tome ključne informacije o obliku objekta. Dobijene ivice objekata se mogu dalje koristiti u algoritmima za prepoznavanje i klasifikaciju objekata.

\section{REFERENCES}

Abdou, I.E., \& Pratt, W.K. (1979). Quantitive Design and Evaluation of Enhancement /Thresholding Egde Detectors. In Proc. of IEEE, 67(5), 753-763.

Amodaj, N., \& Popović, M. (1990). Adaptive procedure for threshold selection in directional derivative edge detectors. In Proc. SPIE 1349, Applications of Digital Image Processing XIII, San Diego, USA (pp. 128-138).

Basu, M. (2002). Gaussian-based Edge-detection Methods-A Survey. IEEE Trans. on Systems, Man, and Cybernetics-Part C, $32,252-260$.

Canny, J. (1986). A Computational Approach to Edge Detection. IEEE Trans. on Pattern Analysis and Machine Intell, 8, 679698.

Frei, W., \& Chen, C.C. (1977). Fast Boundary Detection: A Generalization and a New Algorithm. IEEE Trans. on Computers, 26, 988-998.

Gonzalez, R.C., \& Woods. R.E. (2008). Digital Image Processing. Upper Saddle River, NJ: Prentice Hall.

Gonzalez, R.C., Woods, R.E., \& Eddins, S.L. (2009). Digital Image Processing Using MATLAB, Knoxville, TN: Gatesmark Publishing. 
Macleod, I. (1970). On Finding Structure in Pictures. In Picture Processing and Psychopictorics. New York: Academic Press.

Oskoei, M.A., \& Hu. (2010). A Survey on Edge Detection Methods, Technical Report: CES-506. United Kingdom: University of Essex.

Pinho, A.J., \& Almeida, L.B. (1997). A review on edge detection based on filtering and differentiation. Revista do Detua, 2(1), 113-126.

Popovic, M. (2006). Digitalna obrada slike. Beograd: Akademska misao.

Pratt, W.K. (2007). Digital Image Processing Inc. New York, NY: John Wiley \& Sons.
Russ, J. (2002). The Image Processing Handbook. Boca Raton: CRC Press.

Senthilkumaran, N., \& Rajesh, R. (2009). Edge Detection Techniques for Image Segmentation - A Survey of Soft Computing Approaches. Int. J. of Recent Trends in Engineering, 1, pp. 250-254.

Shin, M.C. (2001). Comparison of Edge Detector Performance through Use in an Object Recognition Task. Computer Vision and Image Understanding, 84, 160-178.

Trussell H.J., \& Vrhel, M.J. (2008). Fundamentals of Digital Imaging. UK: Cambridge University Press. 